\title{
Statistical Characteristics of Mesoscale Convective Systems Initiated over the Tibetan Plateau in Summer by Fengyun Satellite and Precipitation Estimates
}

\author{
Xidi Zhang ${ }^{1,2,3}$, Wenqiang Shen ${ }^{4}$, Xiaoyong Zhuge ${ }^{5,6, *(\mathbb{D}}$, Shunan Yang ${ }^{2,3}$, Yun Chen ${ }^{2,3}$, Yuan Wang ${ }^{1}$, \\ Tao Chen ${ }^{2,3,7}$ and Shushi Zhang ${ }^{5,6}$ \\ 1 Key Laboratory of Mesoscale Severe Weather of Ministry of Education, School of Atmospheric Sciences, \\ Nanjing University, Nanjing 210044, China; zhangxd@cma.gov.cn (X.Z.); yuanasm@nju.edu.cn (Y.W.) \\ 2 National Meteorological Center, China Meteorological Administration, Beijing 100081, China; \\ yangsn@cma.gov.cn (S.Y.); chenyun@cma.gov.cn (Y.C.); chentao@cma.gov.cn (T.C.) \\ 3 CMA-HHU Joint Laboratory for Hydro-Meteorological Studies, Beijing 100081, China \\ 4 Zhejiang Meteorological Observatory, Hangzhou 310051, China; DG1428013@smail.nju.edu.cn \\ 5 Key Laboratory of Transportation Meteorology, China Meteorological Administration, Nanjing 210008, China; \\ zhangss@cma.gov.cn \\ 6 Nanjing Joint Institute for Atmospheric Sciences, Nanjing 210008, China \\ 7 Southern Marine Science and Engineering Guangdong Laboratory (Zhuhai), Zhuhai 519082, China \\ * Correspondence: zhugexy@cma.gov.cn
}

check for

updates

Citation: Zhang, X.; Shen, W.; Zhuge, X.; Yang, S.; Chen, Y.; Wang, Y.; Chen,

T.; Zhang, S. Statistical Characteristics of Mesoscale Convective Systems Initiated over the Tibetan Plateau in Summer by Fengyun Satellite and Precipitation Estimates. Remote Sens. 2021, 13, 1652. https://doi.org/ $10.3390 /$ rs13091652

Academic Editor: Min Min

Received: 21 March 2021

Accepted: 21 April 2021

Published: 23 April 2021

Publisher's Note: MDPI stays neutral with regard to jurisdictional claims in published maps and institutional affiliations.

Copyright: (c) 2021 by the authors. Licensee MDPI, Basel, Switzerland. This article is an open access article distributed under the terms and conditions of the Creative Commons Attribution (CC BY) license (https:// creativecommons.org/licenses/by/ $4.0 /)$.

\begin{abstract}
In order to investigate the key characteristics of mesoscale convective systems (MCSs) initiated over the Tibetan Plateau (TP) in recent years and the main differences in circulation and environmental factors between different types of MCSs, an automatic MCS identification and tracking method was applied based on the data from China's Fengyun satellite and precipitation estimates. In total, 8820 MCSs were found to have been initiated over the TP during the summers from 2013 to 2019 , and a total of $9.3 \%$ of them were able to move eastward out of the TP (EO). The number of MCSs showed a monthly variation, with a maximum in July and a minimum in June, while most EOs occurred in June. Compared with other types of MCSs, EOs usually had a lower cloud-top temperature, a greater rainfall intensity, a longer life duration, more rapid development, larger areas of rainfall and convective clouds, longer tracks and a wider influence range, indicating that EOs are more vigorous than the other types of MCSs. The movement of MCSs is mainly due to the mid- to high-level dynamic conditions, and moisture is an essential factor in their development and maintenance.
\end{abstract}

Keywords: Tibetan Plateau; mesoscale convective systems; Fengyun satellites; temporal and spatial distribution; physical parameters; circulation and environmental features

\section{Introduction}

Strong convective weather systems-such as heavy rain, hail storms, tornados, wind gusts and downdraft flows-are mostly associated with mesoscale convective systems (MCSs). MCSs make a significant contribution to the warm-season precipitation in both the tropics and mid-latitude regions [1,2]. Many studies have revealed the variety and complexity of MCSs over long periods of time and across wide domains [3-7]. MCSs show different features in different regions. MCSs near northern Africa generally propagate westward, and their speed increases at long lifetimes [8-11]. By contrast, eastward-propagating intraseasonal variations are apparent in fractional MCSs near the oceanic warm pool [12-14]. In the tropics and mid-latitudes, the MCS occurrence peaks often take place in the afternoon, and they usually develop rapidly with heavy precipitation and strong winds $[15,16]$. In East China, however, another peak of MCS initiation also exists in the morning [17-19]. Knowing the general characteristics of MCSs during their life cycle makes it possible to 
forecast MCSs' evolution [4]. Quantifying the characteristics of MCSs would therefore provide a useful validation standard and is essential in determining the statistical life cycle features of MCSs in a certain area.

Due to the high altitude, complicated terrain and the unique dynamic and thermodynamic forcing [20-22], the Tibetan Plateau (TP) is an active region for mesoscale convective systems (MCSs) in summer (June-August). These MCSs have a significant influence on extreme weather in the downstream areas of the TP [23-27]. Recent studies have shown that some mesoscale cloud clusters that cause precipitation in the Yangtze River Basin in China can be traced upstream to the TP [28-32]. However, due to the lack of observational data and complex topography of the TP, the study of the weather on the TP has always been difficult.

With recent developments in satellite remote sensing technology, many efforts have been made to study MCSs over the TP. By employing China's Fengyun-1C and the US National Oceanic and Atmospheric Administration (NOAA)-14 satellite data, Shan et al. [33] conducted a statistical study of TP MCSs in 1998-2000. They found that over 70\% MCSs have an irregular shape, and only $30 \%$ present a circular or elliptical outline. Based on hourly infrared observations from the Japanese Himawari-series satellites, Jiang et al. [34] investigated MCSs over the TP in 1994. Their results showed that the initiation and development of MCSs were mainly caused by local thermal effects over the TP, and their movement was correlated with the mean flow between 300 and $200 \mathrm{hPa}$. Jiang and Fan [30] further studied the spatial and temporal features of MCSs over the TP in 1998 and found that there were two convective centers in summer over the southwestern and southeastern $\mathrm{TP}$, and MCSs that affect the Yangtze River Basin mainly occur over the southeastern TP. Mai et al. [35] conducted a statistical study of MCSs over the TP from 2000 to 2016 and studied their relationship with precipitation and southwest vortices. Based on the International Satellite Cloud Climatology Project (ISCCP) data, the initiation, frequency, spatial distribution, life cycle, cloud physics and precipitation of summer MCSs over the TP in 1998-2001 were investigated by Li et al. [36]. Hu et al. [26,37] introduced a new definition for the TP MCSs and conducted a statistical study of MCSs that occurred from 1998 to 2004, comparing the similarities and differences between MCSs over the eastern TP and central TP. Liu et al. [38] used data from China's Fengyun-2 series geostationary satellites to divide TP MCSs into six categories. They explored the differences in spatial-temporal and shape characteristics among all categories.

As mentioned above, some studies have used satellite data with a temporal resolution of three hours or more [26,36,37], whereas others use an hourly resolution [30,33-35]. Most of the studies focused on MCSs before 2010, and the Fengyun satellite data were less used in previous studies. The key characteristics of MCSs over the TP in recent years and the main differences in circulation and environmental factors between different types of MCSs are still unknown. As the zenith angle is less than that of other satellites, the hourly data from Fengyun satellites should be more reliable for studying MCSs over the TP. The single infrared brightness temperature criteria used for identifying MCSs in previous studies may result in misclassification in regions with high mountains, large amounts of cirrus clouds and cold surfaces under clear sky conditions, where the infrared brightness temperature is low. In general, precipitation is used to characterize the convective intensity of MCSs [39-41]. It is therefore essential to combine Fengyun infrared brightness temperature data with the rain intensity [40-42] to investigate the statistical characteristics of MCSs over the TP.

The objective of this study was to investigate the key characteristics of MCSs over the TP in 2013-2019 by the combination of Fengyun satellite data and rain intensity. MCSs were classified into four types, and their features were examined and compared. The paper is organized as follows: Section 2 presents our data and methods, and Section 3 discusses the key statistical characteristics of MCSs over the TP. Sections 4 and 5 present the discussion and conclusions, respectively. 


\section{Materials and Methods}

\subsection{Data}

In this study, the TP is defined as the region within $26-40^{\circ} \mathrm{N}$ and $75-103^{\circ} \mathrm{E}$ where the terrain height exceeds $3000 \mathrm{~m}$ (Figure 1). MCSs initiated over the TP from June to August in 2013-2019 were analyzed.

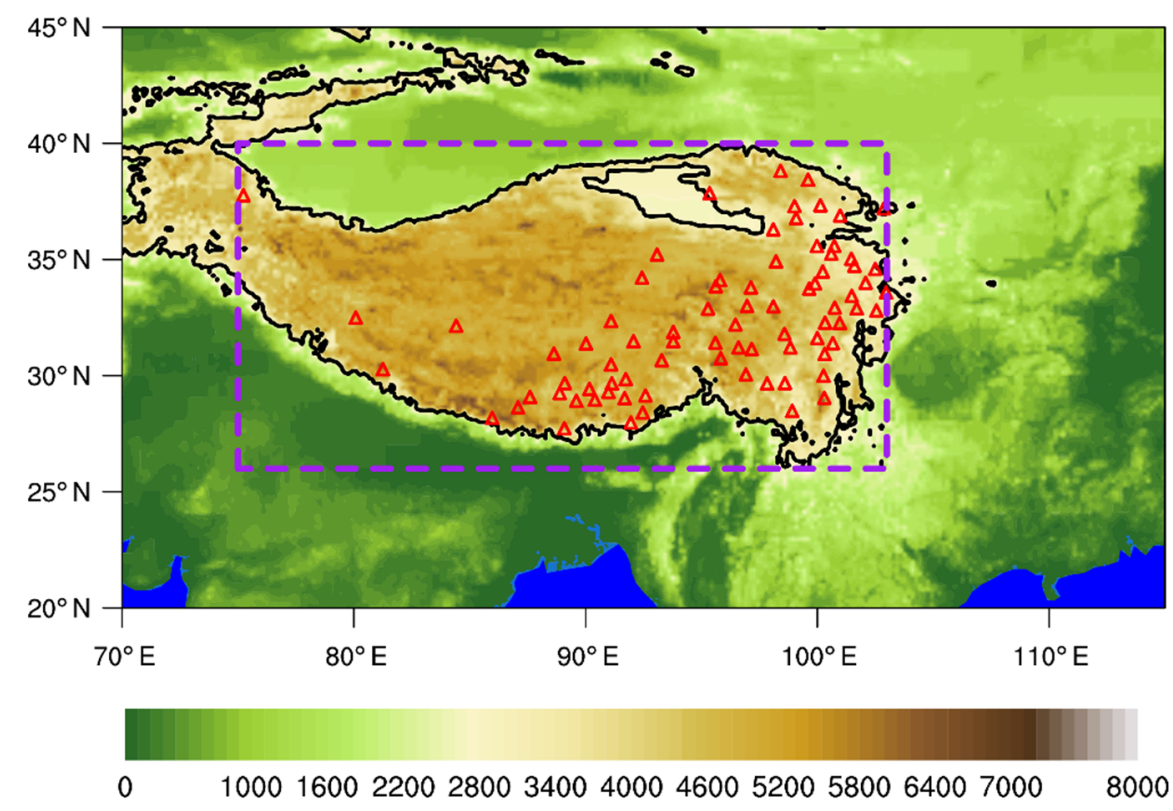

Figure 1. Terrain height of the TP (shading; units: $\mathrm{m}$ ). TP is defined as the region within $26-40^{\circ} \mathrm{N}$ and $75-103^{\circ} \mathrm{E}$ (purple dashed rectangle) where the terrain height exceeds $3000 \mathrm{~m}$ (black line). The red triangles show the location of automatic weather stations on the TP.

We used hourly $0.1^{\circ} \times 0.1^{\circ}$ infrared brightness temperature observations from the Fengyun-2E geostationary meteorology satellites for 2013-2014 and from Fengyun-2G for 2015-2019. We also used the China Merged Precipitation Analysis (CMPA) dataset, which combines hourly rain gauge observations with the NOAA/Climate Prediction Center Morphing $(\mathrm{CMORPH})$ precipitation product on a $0.1^{\circ} \times 0.1^{\circ}$ grid. In general, more than $50 \%$ of the grid boxes with a $0.1^{\circ}$ resolution in eastern China contain at least one rain gauge, whereas there is usually no station within a $500 \mathrm{~km}$ radius of the grid boxes in western China (west of $90^{\circ} \mathrm{E}$ ). In these regions with sparsely distributed automatic weather stations, some unrealistic rainfall centers are usually depicted. Even so, this dataset in general has a smaller bias and root mean square error than other precipitation datasets, and it captures the major temporally varying features of hourly precipitation during the period of intense rainfall regardless of gauge density [43]. To analyze the atmospheric circulations, the hourly $0.25^{\circ} \times 0.25^{\circ}$ European Center for Medium-Range Weather Forecasts Reanalysis 5 (ERA-5) dataset was used.

\subsection{MCS Identification and Tracking Methods}

Following the methods of Ai et al. [44], the infrared brightness temperature and precipitation data were used to identify and track MCSs via the following steps:

(1) Step 1: cloud identification

Based on the infrared brightness temperature, we classify clouds into two categories: convective shield (CS, brightness temperature $<240 \mathrm{~K}$ ) and convective core (CC, brightness temperature $<225 \mathrm{~K})$.

(2) Step 2: matching CS with precipitation

The rain associated with CS is defined as follows (Figure 2): An external rectangle (black dashed line) is drawn around each CS (orange contours), and a circle is drawn 
centered over the CS with a radius equal to the maximum distance from the centroid (red cross) to the four apexes of the bounding box. The precipitation in the black circle is defined as the rain matched to a CS.

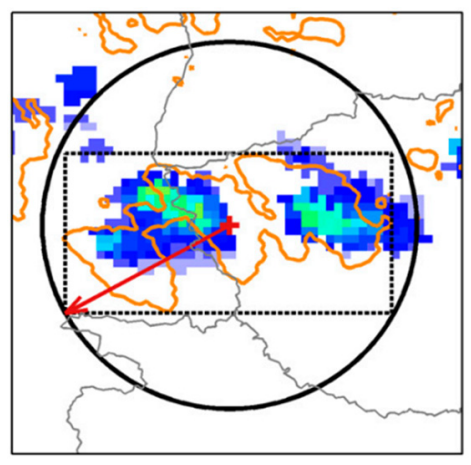

Figure 2. Matching of precipitation to CS. The orange contour represents the region with an infrared brightness temperature of $240 \mathrm{~K}$, and the red cross marks the centroid of the CS. The red arrow (radius) is the maximum distance from the centroid to the four apexes of the bounding box (black dashed rectangle). A circular search range (bold black circle) can then be drawn to find the associated rain (shading) within a CS (adapted from [44]).

\section{(3) Step 3: identification and tracking methods}

An MCS is identified by a combination of satellite and precipitation information. The formation time (FT) of an MCS is defined as when the following four criteria are first met in three successive hours: (1) the CC exists, (2) the maximum rain intensity exceeds $2 \mathrm{~mm} \cdot \mathrm{h}^{-1}$ (this criterion is from the rain intensity range of weak deep convective precipitation over the TP [45]), (3) the area of CS is over $5000 \mathrm{~km}^{2}$ [10,46] and (4) the total area of the precipitation region is above $200 \mathrm{~km}^{2}$.

Starting from FT, the MCSs are tracked backward and forward based on the areal overlap method. A cloud at a later hour corresponds to the cloud at an earlier time if their CS overlapping area is more than $10 \%$. The initiation time (IT) of the MCS is defined as the earliest time that satisfies the backward tracking criterion, and the dissipation time (DT) is defined as when the maximum rain intensity is lower than $2 \mathrm{~mm} \cdot \mathrm{h}^{-1}$ (Figure 3 ). If several clouds in the later hour meet this condition, the one with the largest overlapping area is considered to be the continuous MCS. If two or more MCSs merge together, then the merged MCS is assumed to be a continuation of the largest MCS and the smaller MCSs are terminated. When an MCS splits into several smaller parts, the largest part is assumed to be the continuous MCS and the smaller parts are assumed to be new MCSs if they satisfy the criteria of an MCS.

Previous studies have identified MCSs based on different infrared brightness temperatures. Machado et al. [15] used 245 and $218 \mathrm{~K}$ thresholds to define convective systems and the active deep convective cells embedded within the convective systems. Zheng et al. [17] used $221 \mathrm{~K}$ as the criterion to identify MCSs in China and its vicinity, and Mathon and Laurent [10] employed 233 and $213 \mathrm{~K}$ to analyze deep convection and the most active part of convective systems, respectively. There is no universal brightness temperature threshold for MCS identification, and changes within $5 \mathrm{~K}$ do not make a significant difference between the results [44]. The 240 and $225 \mathrm{~K}$ thresholds used for identifying MCSs in this study are derived from the distribution range of the infrared brightness temperature of deep weak convective precipitation over the TP [45], and introducing the precipitation criterion helps to reduce the misclassification of high cirrus clouds or stratus clouds with low rain rates as MCSs. 


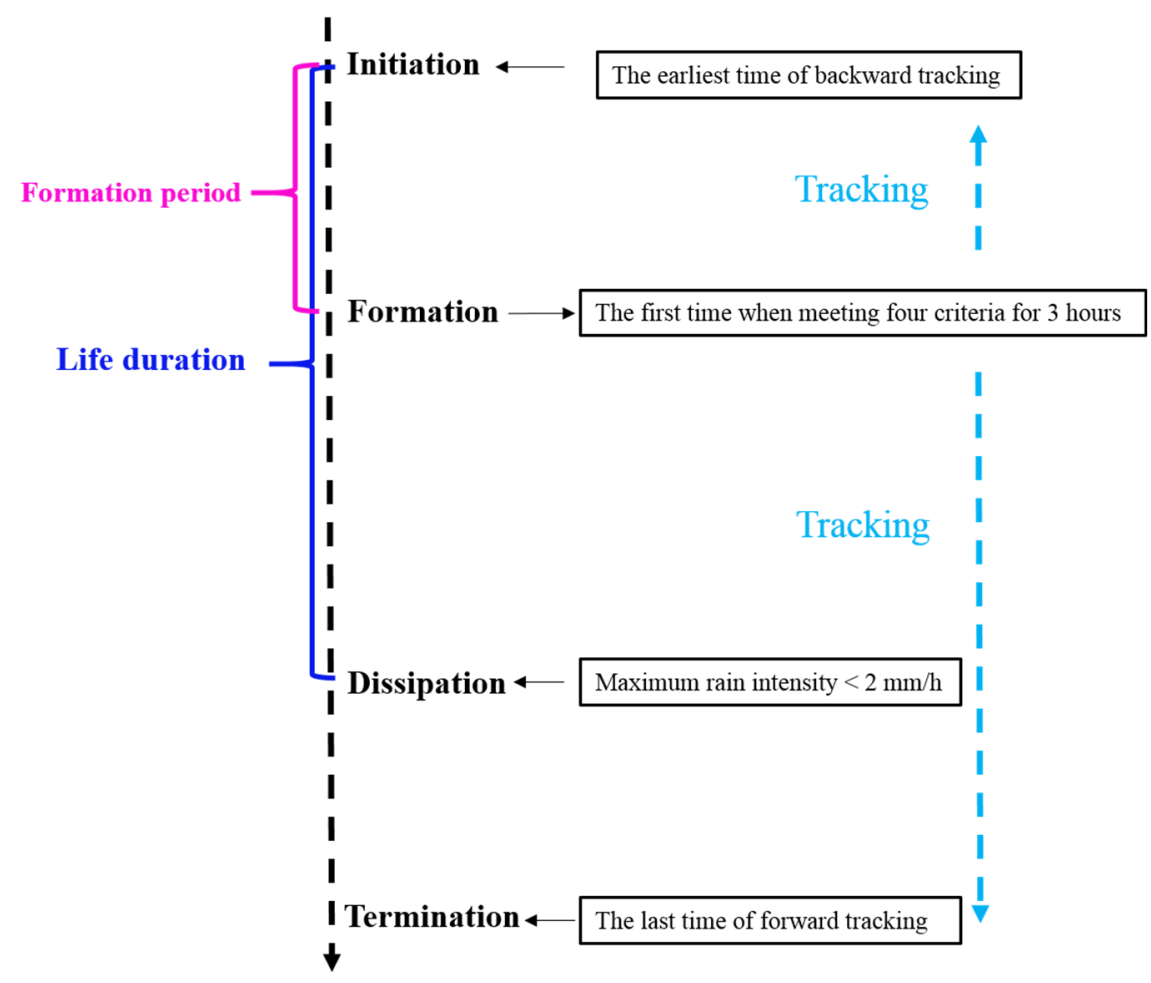

Figure 3. Flow diagram showing the procedure for the identification and tracking of MCSs.

The tracking method used in this study is similar to that in [44], except that the infrared brightness temperature, rain intensity and area criteria are modified for the TP region. Compared with [47], both forward and backward tracking and the rain intensity are introduced in this study to improve the tracking processes. The areal overlap method is based on the assumption that temperature distribution and area of convective systems do not change strongly in a short time. The small overlapping rate used in this study enables the tracking of small convective clouds right after convective initiation. By testing, it was determined that the results were slightly affected when the overlapping rate was set to $20 \%$.

(4) Step 4: physical parameters

In order to characterize the MCSs' features quantitatively, some life cycle physical parameters are introduced. The life duration that characterizes the time of activities of MCSs is calculated as the time between IT and DT. The formation period ratio (FPR) is the time between IT and FT divided by life duration and multiplied by $100 \%$ :

$$
\mathrm{FPR}=\frac{(F T-I T)}{\text { life duration }} \times 100 \%
$$

The formation speed of MCSs can be measured by FPR, and a smaller FPR represents a faster formation speed. The life duration and FPR for each MCS, as well as the minimum infrared brightness temperature $\left(\mathrm{BT}_{\min }\right)$, the maximum rate intensity $\left(\mathrm{P}_{\max }\right)$, the maximum associated rain area $\left(\mathrm{PA}_{\max }\right)$, the maximum $\mathrm{CS}$ area $\left(\mathrm{CSA}_{\max }\right)$ and the maximum $\mathrm{CC}$ area $\left(\mathrm{CCA}_{\max }\right)$ during MCS life cycle are examined.

\subsection{Classification of MCSs}

At any given hour, the location of the centroid of an MCS is taken as its position, and the direction of movement is determined by the line between its initiation and dissipation points. If the direction of movement lies between the northeast and southeast (45-135 clockwise from the true north), then it is defined as eastward moving. If the direction of movement lies between the southwest and southeast $\left(135-225^{\circ}\right.$ clockwise from the true 
north), then it is defined as southward moving. If the direction of movement lies between southwest and northwest $\left(225-315^{\circ}\right.$ clockwise from the true north), then it is defined as westward moving. Here, we define $103^{\circ} \mathrm{E}$ as the eastern boundary of the TP. If an MCS moves further east than $103^{\circ} \mathrm{E}$, then it is considered to have vacated the TP. Based on their direction of movement and tracks, the MCSs initiated over the TP can be classified roughly into four types: (a) eastward moving out of the TP (EO), (b) southward moving (SM), (c) westward moving (WM) and (d) eastward moving but not out of the TP (EN), and SM, WM and EN are all defined as non-EOs.

\section{Results}

A total of 8820 MCSs were identified over the TP during seven summers, equivalent to about four MCSs per day, which demonstrates that MCSs are very active over the TP in summer. Of all the MCSs, there were 820 (9.3\%) EOs, 1739 (19.7\%) SMs, 1640 (18.6\%) WMs and 4621 (52.4\%) ENs. Therefore, the occurrence frequency of EOs is the lowest, while that of ENs is the highest.

\subsection{Circulation and Environmental Features}

In general, weather systems move along the direction of the mid-level mean flow, which is usually called "steering flow". The mean zonal wind (U), meridional wind (V) and relative humidity (RH) of all MCS areas were therefore calculated from the ERA5 reanalysis dataset to study the vertical distribution of circulation and environmental features of different types of MCSs. Figure $4 a, b$ shows that the westerly (northerly) wind is strongest for EOs (SMs), which favors their eastward (southward) movement out of the TP. The differences in U and V among each type of MCS mainly appear in the upper troposphere, indicating that the movement of MCSs is mainly due to the mid- to high-level dynamic conditions. The $U$ and V of ENs are both too small for them to move out from the $\mathrm{TP}$, and the easterly wind in the low to middle troposphere contributes to the westward movement of WMs. The RH levels of EOs and SMs are greater than those of WMs and ENs (Figure 4c), because moisture is an essential factor in the development and maintenance of MCSs.
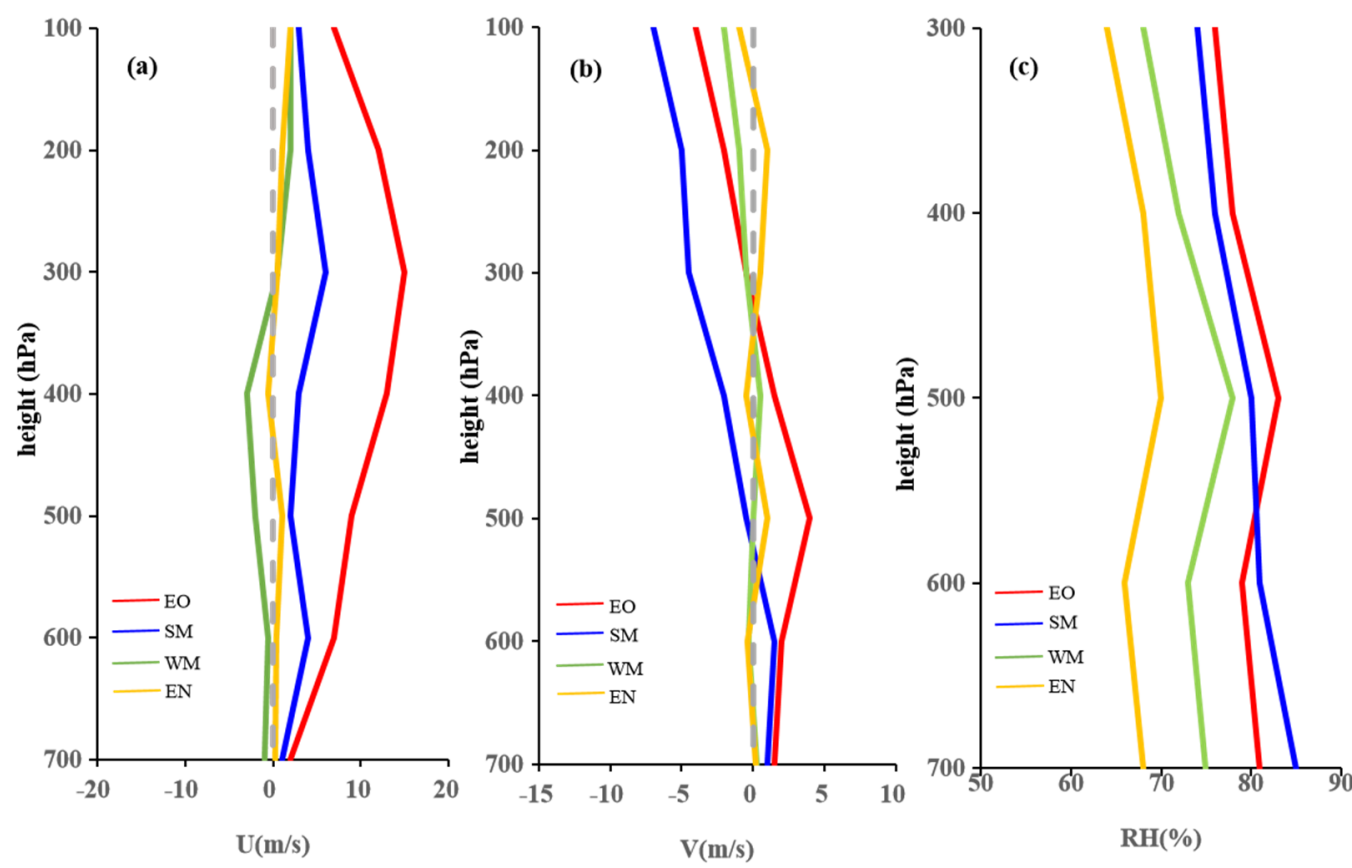

Figure 4. Circulation and environmental features of each type of MCS. (a) Zonal winds; (b) meridional winds; (c) relative humidity. Gray, red, blue, green and yellow lines represent the zero value, EO, SM, WM and EN, respectively. 


\subsection{Spatial Distribution of Occurrence and Tracks}

Figure 5 shows the spatial distribution of MCSs initiated over the TP. There was much more MCS activity over the southern TP than over the northern TP, with two centers of maximum activity along $30^{\circ} \mathrm{N}$ over the southern TP. The western center with two peaks was located over the southwestern TP around $85-90^{\circ} \mathrm{E}$, and the eastern center was located over the southeastern TP near $100^{\circ} \mathrm{E}$ (Figure 5a), which is in agreement with previous work $[30,35,36]$. Most of the EOs were initiated over the southeastern TP east of $95^{\circ} \mathrm{E}$ (Figure $5 b$ ), especially at the eastern boundary of the TP, and the center of maximum activity was located near $30^{\circ} \mathrm{N}$ and $102^{\circ} \mathrm{E}$. Most of the SMs were also initiated in this area, and the southwestern TP had a high frequency of SMs, although at a lower density (Figure 5c). Most WMs occurred in the western center near $90^{\circ} \mathrm{E}$ (Figure $5 \mathrm{~d}$ ), whereas the highest frequency of ENs occurred in the western center near $85^{\circ} \mathrm{E}$, with a slightly weaker center over the southeastern TP (Figure 5e). Therefore, the southeastern center of activity over the TP was mainly due to EOs and SMs, whereas WMs and ENs mainly occurred over the western one.

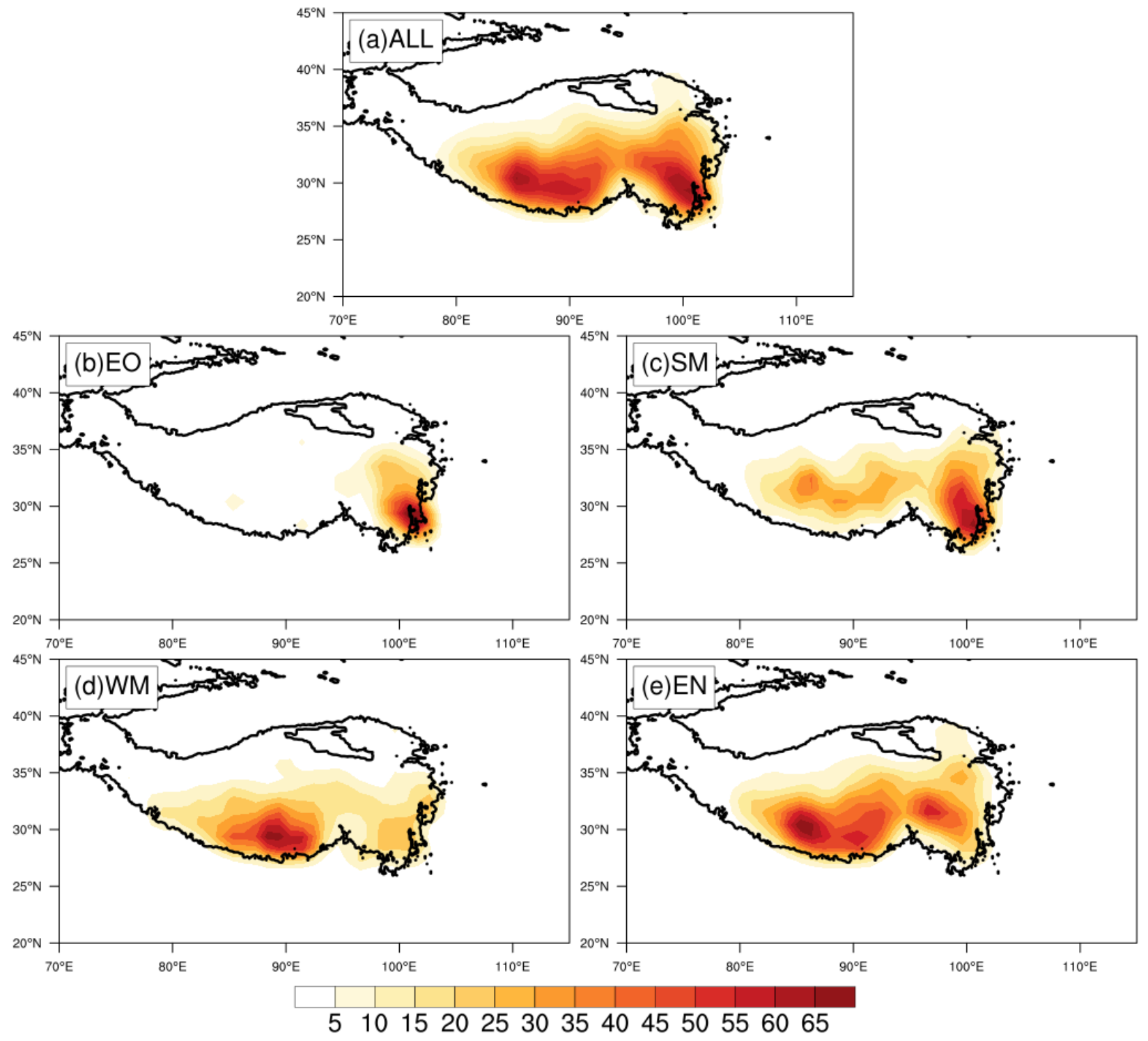

Figure 5. Spatial distribution of MCS initiation over the TP on $1^{\circ} \times 1^{\circ}$ grids. (a) All MCSs; (b) EOs; (c) SMs; (d) WMs; (e) ENs. 
The spatial distribution of MCSs initiated in June, July and August is shown in the Supplementary Material. In June, there was much more MCS activity over the southeastern TP than over the southwestern TP. The western centers of SMs, WMs and ENs were greatly weakened. However, much more SMs, WMs and ENs occurred over the southwestern center in July and August than in June. From June to August, EOs always only occurred over the southeastern TP, and there was more SM (WM) activity over the southeastern (southwestern) TP than the other. The southeastern center with more ENs appeared in June, while the southwestern one was enhanced in July and August.

EOs mainly influenced the regions east of $90^{\circ} \mathrm{E}$, and most of them affected southwestern China after they had vacated the TP (Figure 6a). Non-EOs affected almost all of the TP with shorter tracks, and they could vacate the TP in other directions. A total of 311 SMs moved southward out of the TP, and they moved mostly to the south of the TP after vacating the TP (Figure 6b). A total of 129 WMs moved westward out of the TP, and some even reached India (Figure 6c). The statistical results indicate that over $85 \%$ of MCSs dissipated within the TP.
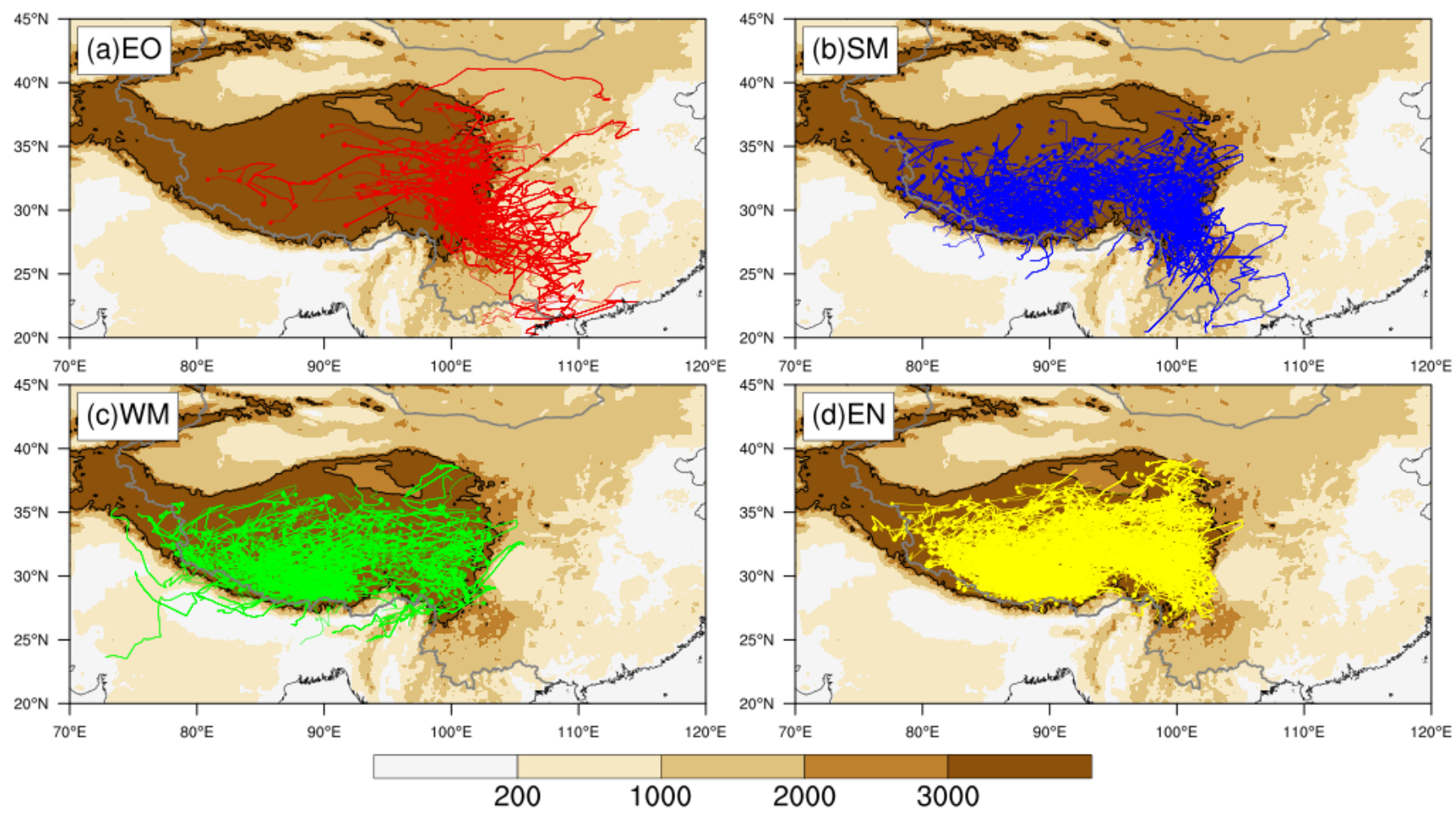

Figure 6. Initiation location (points in color) and tracks (thin curves in color) of MCSs initiated over the TP. (a) EOs; (b) SMs; (c) WMs; (d) ENs. The shading area and the black line represent the terrain and the $3000 \mathrm{~m}$ terrain height, respectively.

\subsection{Lifespan}

The life duration distributions of SMs, WMs and ENs showed similar features but were different from the life duration distribution of EOs. During the whole summer, the mean life duration of EOs was $\sim 22 \mathrm{~h}$, nearly twice that of non-EOs $(\sim 12 \mathrm{~h})$. About $78.9 \%$ of the non-EOs lasted less than $15 \mathrm{~h}$, and the number of non-EOs with a life duration of more than $20 \mathrm{~h}$ was significantly reduced, whereas $70.1 \%$ of the EOs lasted longer than $15 \mathrm{~h}$. In addition, 25\% EOs lasted for more than $30 \mathrm{~h}$, and very few non-EOs lasted this long (Figure 7a). In July, 40\% EOs lasted longer than $30 \mathrm{~h}$, and the corresponding proportions in June and August were 22\% and 17\% (Figure $7 \mathrm{~b}-\mathrm{d}$ ), indicating that EOs with longer life duration are more likely to occur in July. By virtue of the westerly jet, no WMs lasted longer than $18 \mathrm{~h}$ in June. As most EOs were initiated near the east edge of the $\mathrm{TP}$, it was much easier for them to move eastward out of the TP under stronger westerly 
wind conditions. Once they reached areas east of the TP with lower elevations, increased moisture supplement usually made them intensify and last longer.
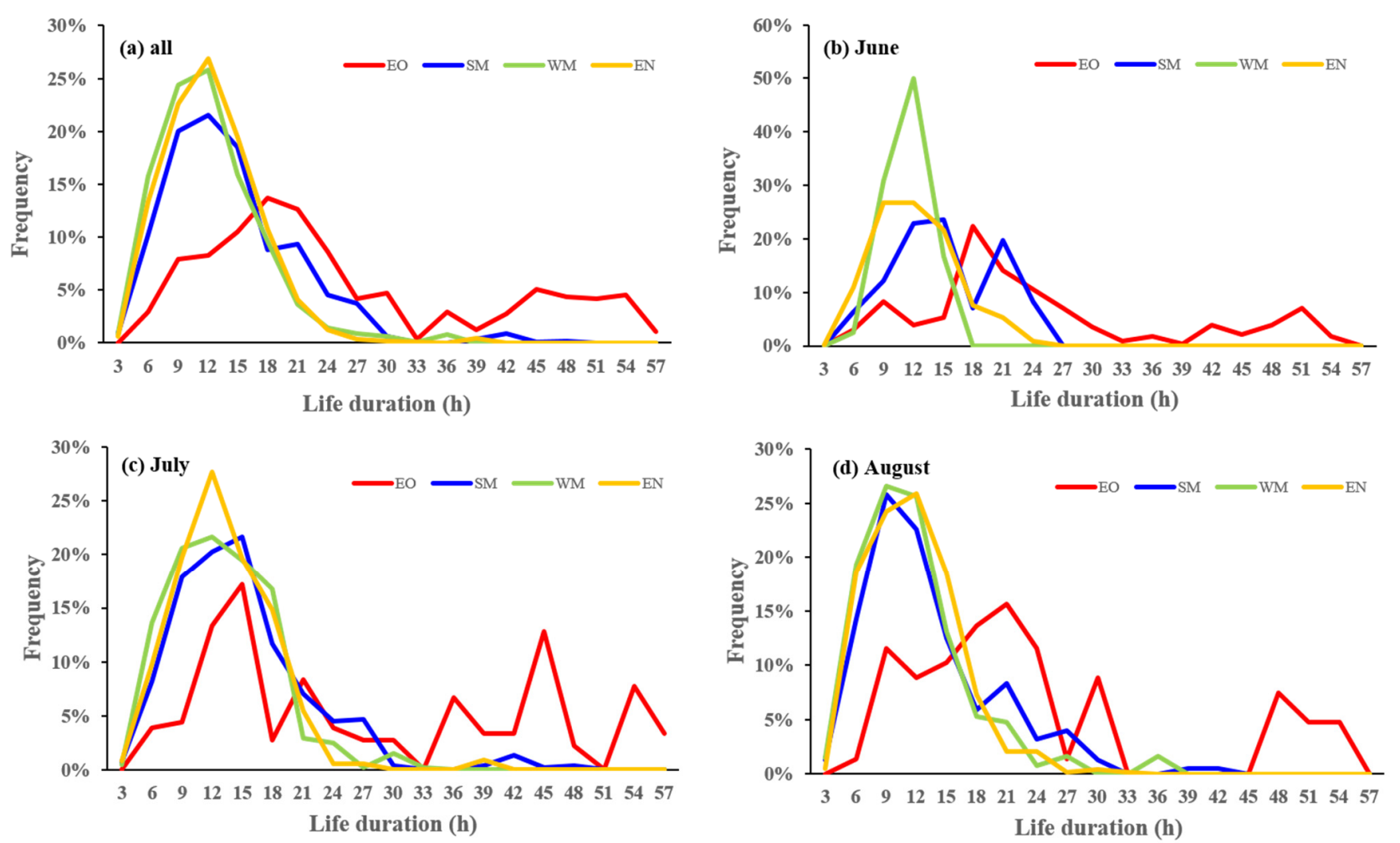

Figure 7. Life duration distribution of EOs (red), SMs (blue), WMs (green) and ENs (yellow). (a) Whole summer; (b) June; (c) July; (d) August.

\subsection{Temporal Variations}

\subsubsection{Annual Variations}

Figure 8 shows the annual variation of MCS occurrence number from 2013 to 2019. The maximum occurrence number of MCSs was 1984 in 2016, and the minimum was 670 in 2019. In each year, nearly half of the MCSs were ENs, and the proportions of SMs and WMs both ranged between 10 and 20\%. The proportion of EOs was the smallest and varied considerably, with a maximum of $12.48 \%$ in 2015 and a minimum of $8.31 \%$ in 2013 .

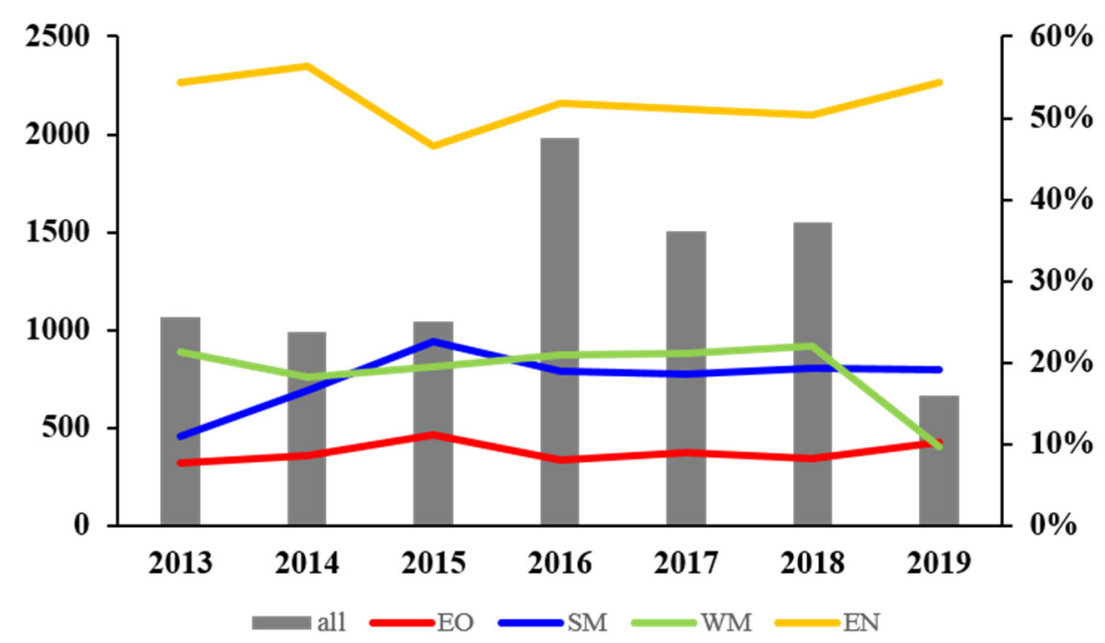

Figure 8. Annual variation of MCS number (gray columns) and proportion of EOs (red), SMs (blue), WMs (green) and ENs (yellow) from 2013 to 2019. 


\subsubsection{Monthly Variations}

The monthly variation of MCS number over the TP is shown in Figure 9. MCSs initiated in July and August accounted for over $80 \%$ of the total MCSs in summer, and most of the SMs and ENs (WMs) appeared in July (August), whereas the EOs showed an opposite trend. The proportion of EOs was much lower in July (7.2\%) and August $(6.43 \%)$ than in June $(24.3 \%)$, which is consistent with previous results [35]. This remarkable monthly variation was mainly due to the variation in latitude of the westerly jet over the TP $[26,48]$ and the enhancement of the South Asia high in July and August. The westerly jet at $200 \mathrm{hPa}$ jumped from the southern to the northern TP with the onset of the monsoon in June, and the westerly wind over the TP was (not) favorable for EOs (WMs) moving eastward (westward) (Figure 10a). In July (August), the South Asia high was established over the TP and southeastern (southwestern) TP was under the northerly (easterly) winds, which favored the movement of SMs (WMs) (Figure 10b,c) [26]. Convective available potential energy (CAPE) is a crucial factor in the initiation and organization processes of MCSs. Figure 10e shows that, in July, there were two CAPE maximum centers over the southeastern and southwestern TP corresponding to the two initiation centers, and they were slightly larger than the CAPE maximum center in August (Figure 10f) and much larger than the CAPE maximum center in June (Figure 10d). A larger CAPE corresponded to more frequent MCS initiation, which indicated that CAPE is one of the most important factors that result in different numbers of MCSs in each month.

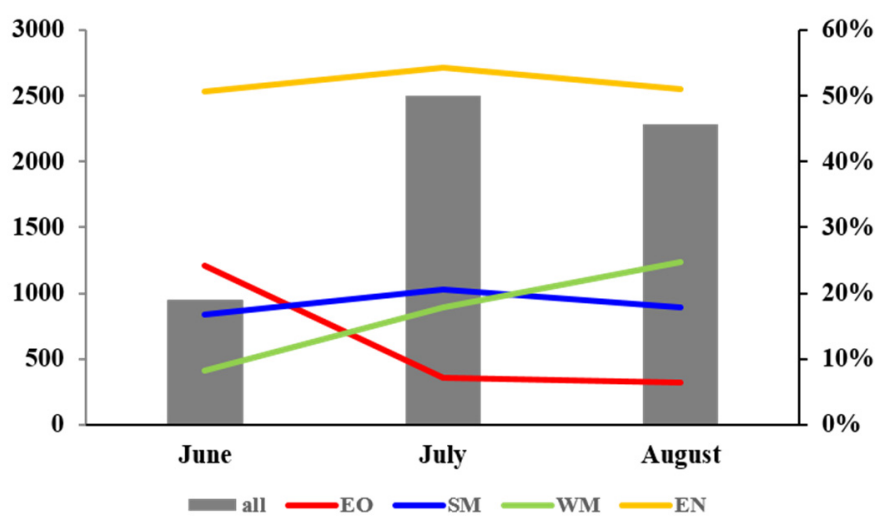

Figure 9. Monthly variation of MCS number (gray columns) and proportion of EOs (red), SMs (blue), WMs (green) and ENs (yellow) from 2013 to 2019.

\subsubsection{Diurnal Variations}

The UTC was converted to local standard time (LST) to investigate the diurnal variation features of MCSs because the Tibetan Plateau spans multiple time zones. The combined non-EO was used because the SMs, WMs and ENs showed similar trends. The IT frequency increased rapidly from 12:00 LST and peaked at 13:00-16:00 LST due to the solar radiation, and then decreased significantly from 18:00 LST to the next day (Figure 11a), which is consistent with previous reports $[17,35]$. The maximum frequency of EOs occurred at around 15:00 LST, and the corresponding time for non-EOs happened an hour later. About $70.8 \%$ of EOs were initiated in the afternoon (12:00-18:00 LST), and the corresponding frequency of non-EOs was $58.1 \%$, indicating that EOs need more solar radiation for initiation than non-EOs. 

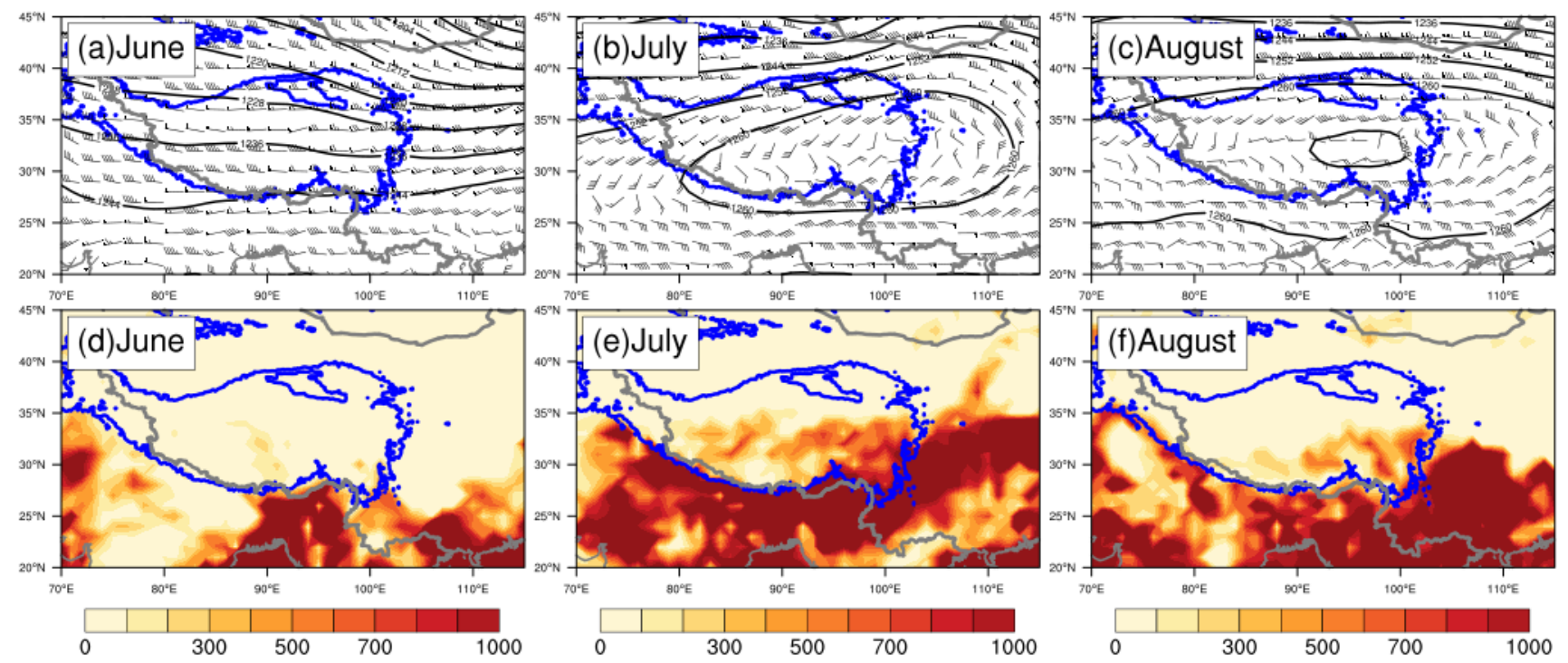

Figure 10. Mean geopotential height (black lines, units: dagpm), wind fields at $200 \mathrm{hPa}$ (top panel) and CAPE (bottom panel) in (a,d) June, (b,e) July and (c,f) August.
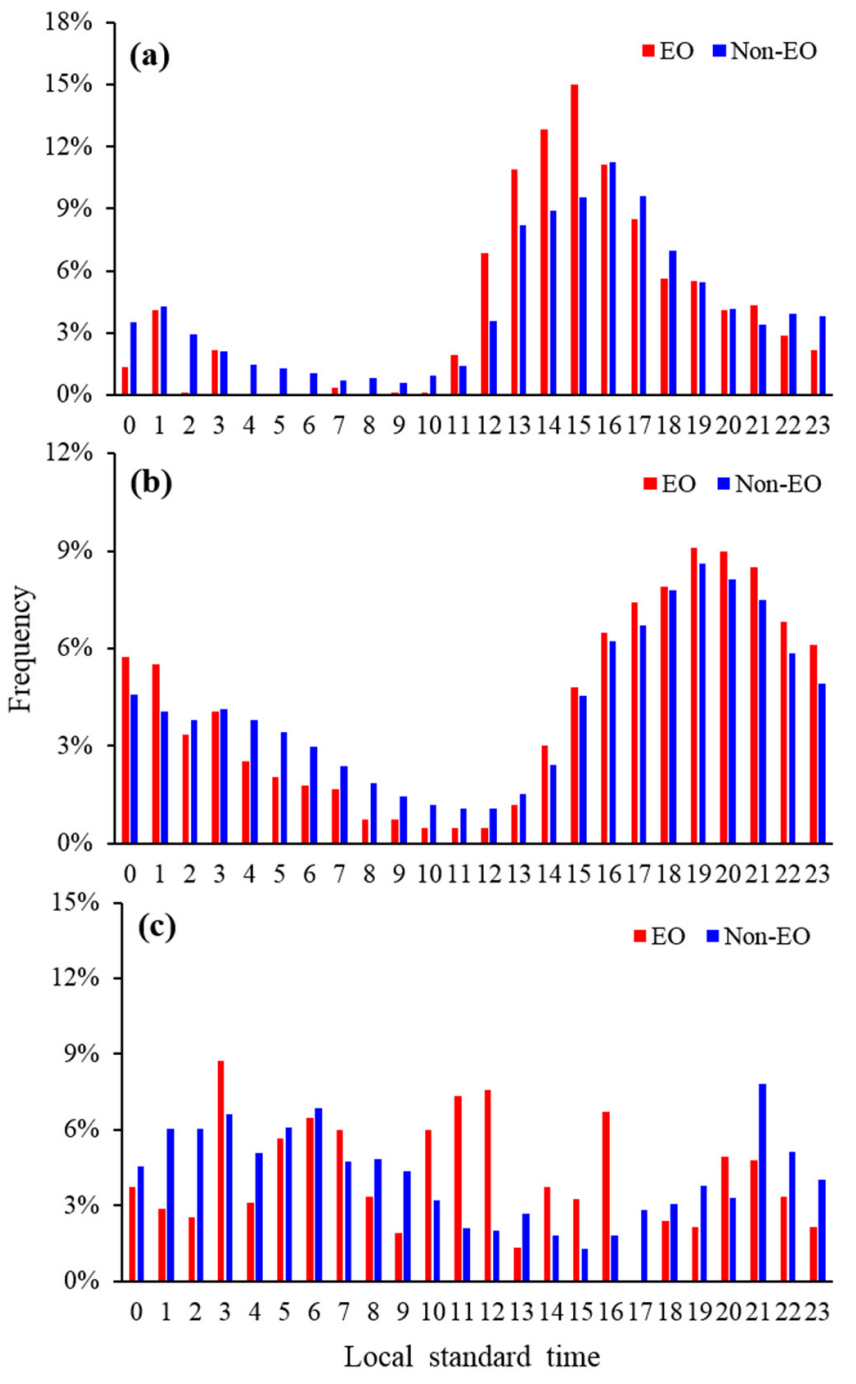

Figure 11. Diurnal variation of EOs (red) and non-EOs (blue) from 2013 to 2019. (a) Initiation time; (b) formation time; (c) dissipation time. 
The FT frequency of EOs and non-EOs (Figure 11b) showed the same trend as IT, but occurring a few hours later. The frequency of EOs (38\%) was close to that of non-EOs (36\%) at night (22:00-06:00 LST) and was much more than that of IT (12\% and 23\% for EOs and non-EOs, respectively), which indicates that the MCS formation processes depend on the environmental circulation and other factors besides solar radiation. The DT frequency peak for EOs (non-EOs) occurred around 10:00-12:00 (01:00-06:00) LST (Figure 11c), corresponding to the results calculated from IT and the mean life duration.

\subsection{Physical Parameters}

There was no obvious difference among the physical parameters of SMs, WMs and ENs, whereas EOs showed some unique characteristics. The distribution of $\mathrm{BT}_{\text {min }}$ showed that nearly $50 \%$ of EOs reached a $\mathrm{BT}_{\text {min }}$ less than the average value of $208 \mathrm{~K}$ (Figure 12a), whereas only $20 \%$ of non-EOs did so and the average was $214 \mathrm{~K}$ (Figure $12 \mathrm{~g}, \mathrm{~m}, \mathrm{~s}$ ), which

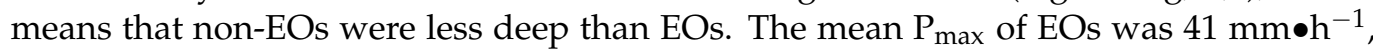
and nearly half of them experienced a maximum rain rate over $40 \mathrm{~mm} \bullet \mathrm{h}^{-1}$ (Figure $12 \mathrm{~b}$ ). The $P_{\max }$ of non-EOs was much less, with an average of $20-26 \mathrm{~mm}^{-1} \mathrm{~h}^{-1}$ (Figure $12 \mathrm{~h}, \mathrm{n}, \mathrm{t}$ ). Note that the $\mathrm{P}_{\max }$ features of MCSs over the TP had not been examined before, because the temporal-spatial resolution of daily rain data and accuracy of satellite precipitation products used in previous studies were too coarse to provide sufficient details. Over 70\% of EOs and less than $50 \%$ of non-EOs spent two-fifths of their life duration undergoing the formation processes, with averages of $26 \%$ and around $40 \%$, respectively, indicating that EOs developed faster (Figure $12 \mathrm{c}, \mathrm{i}, \mathrm{o}, \mathrm{u}$ ). $\mathrm{PA}_{\max }$ and $\mathrm{CSA}_{\max }$ mainly ranged between $10^{4}$ and $10^{6} \mathrm{~km}^{2}$, both with an expected value of over $10^{5} \mathrm{~km}^{2}$ for EOs, which are significantly greater than those of non-EOs (Figure 12d,e,j,k,p,q,v,w). CCA max mainly ranged between $10^{3}$ and $10^{5} \mathrm{~km}^{2}$, and $13 \%(2 \%)$ of EOs (non-EOs) exceeded $10^{5} \mathrm{~km}^{2}$ (Figure $12 \mathrm{f}, 1, \mathrm{r}, \mathrm{x}$ ).
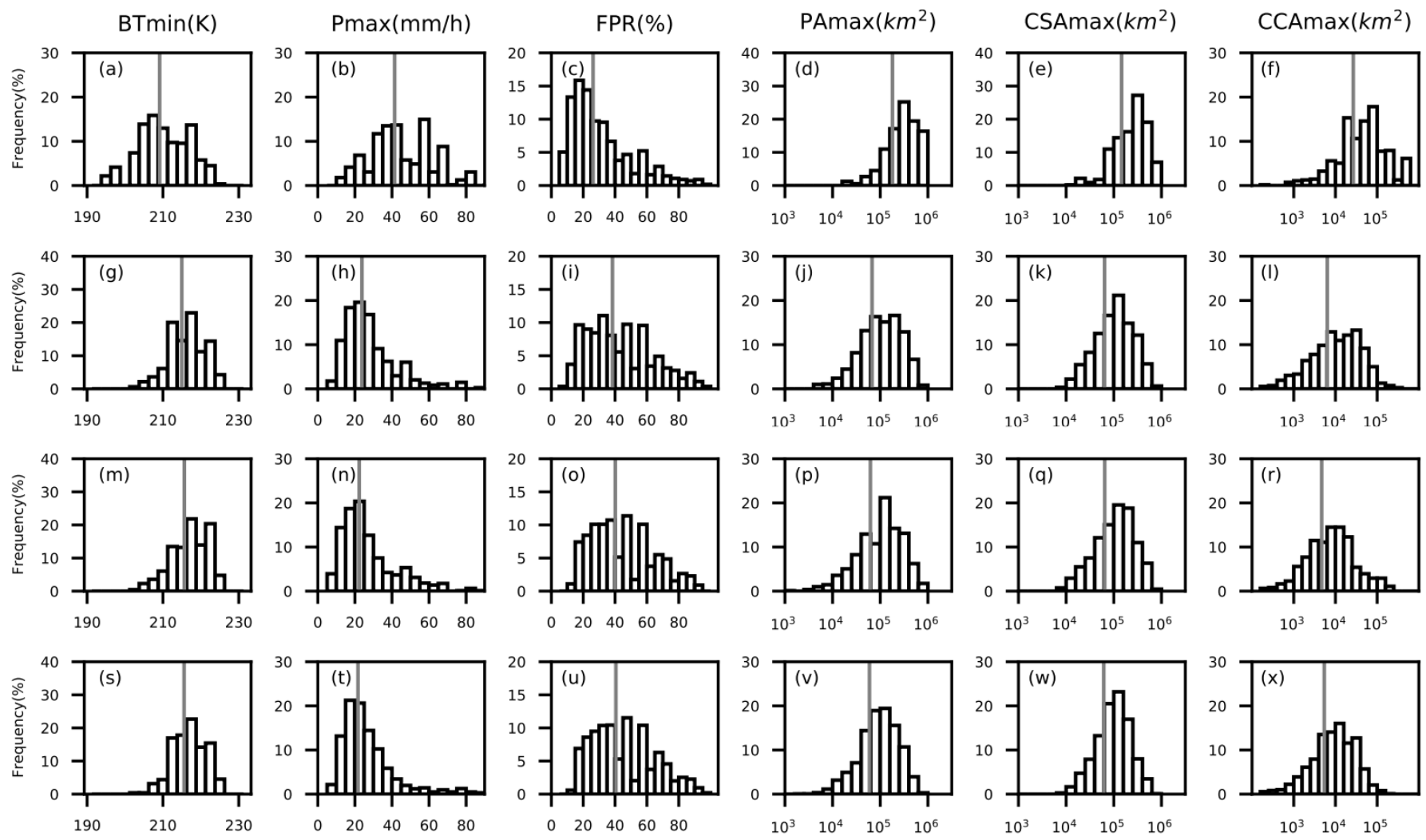

Figure 12. Distribution of physical parameters of MCSs. (a-f) EOs; (g-1) SMs; (m-r) WMs; (s-x) ENs. The gray vertical lines represent the average value, and BTmin, Pmax, FPR, PAmax, CSAmax and CCAmax represent the lowest infrared brightness temperature, max precipitation intensity, formation percentage, max precipitation area, max CS area and max CC area, respectively. 
The spatial distribution of $\mathrm{BT}_{\min }$ and $\mathrm{P}_{\max }$ are shown in Figures 13 and 14. For all MCSs, both $\mathrm{BT}_{\min }$ and $\mathrm{P}_{\max }$ presented spatial patterns similar to those of MCS occurrences (Figures $13 \mathrm{a}$ and $14 \mathrm{a}$ ). The $\mathrm{BT}_{\min }$ maximum center of each type of MCS was located slightly downstream of the moving direction to the initiation area (Figure $13 \mathrm{~b}-\mathrm{e}$ ), and the $\mathrm{P}_{\max }$ maximum center further was located slightly downstream of the moving direction to the $\mathrm{BT}_{\text {min }}$ maximum center (Figure $14 \mathrm{~b}-\mathrm{e}$ ). Due to the more abundant moisture over the lower reaches of the TP, rain intensity often reached its peak when EOs moved eastward out of the TP.

Compared with non-EOs, EOs had a lower cloud-top temperature, greater rainfall intensity, longer life duration, more rapid development, larger areas of rainfall and convective clouds, longer tracks and a wider influence range, indicating that EOs were more vigorous. The $\mathrm{BT}_{\min }$ and $\mathrm{P}_{\max }$ maximum centers of each type of MCS were located slightly downstream of the moving direction to the initiation area, and the maximum rain intensity of EOs was located east of the eastern boundary of the TP.

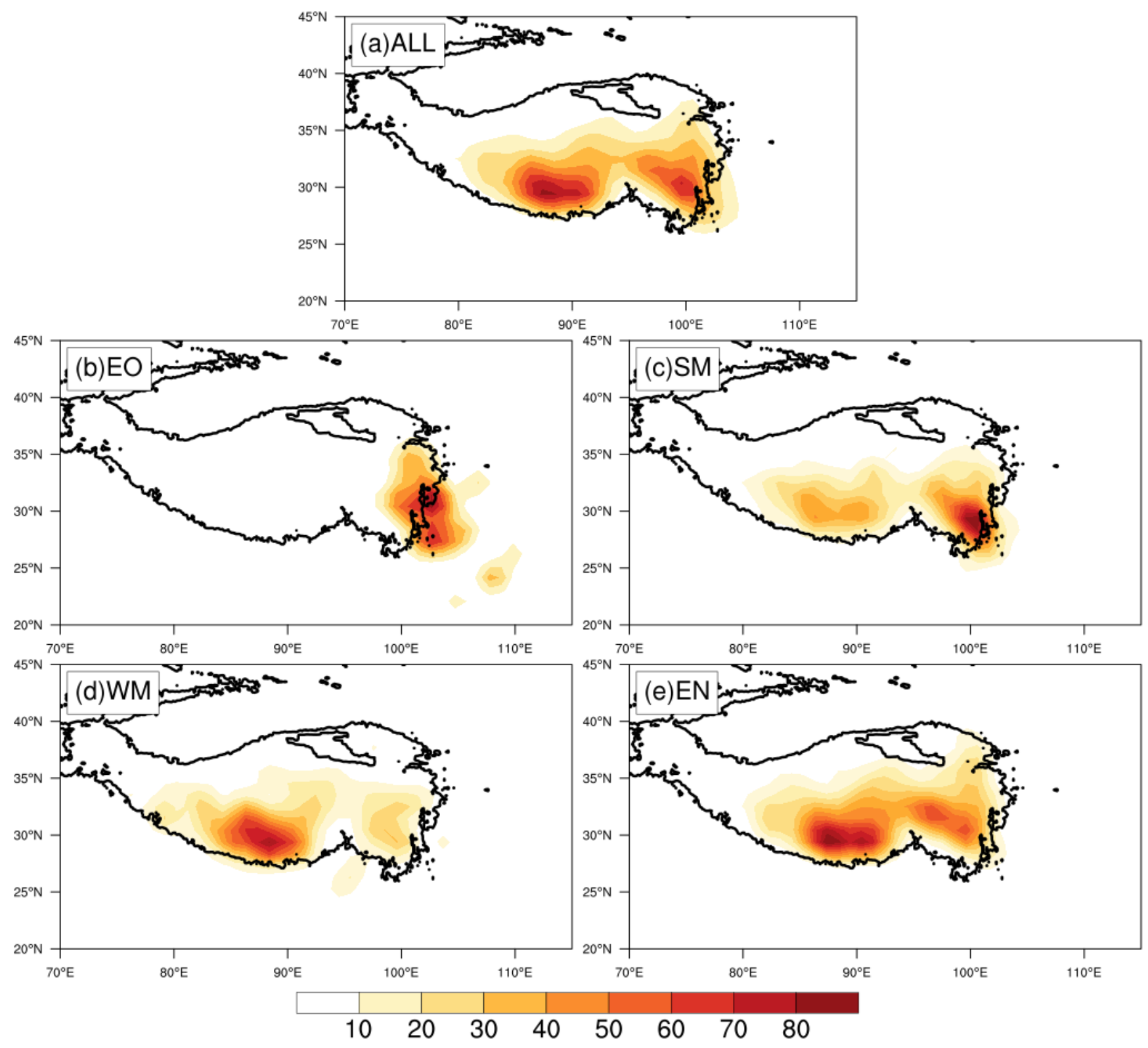

Figure 13. Spatial distribution of $\mathrm{BT}_{\min }$ over the $\mathrm{TP}$ on $1^{\circ} \times 1^{\circ}$ grids. (a) All MCSs; (b) EOs; (c) SMs; (d) WMs; (e) ENs. 


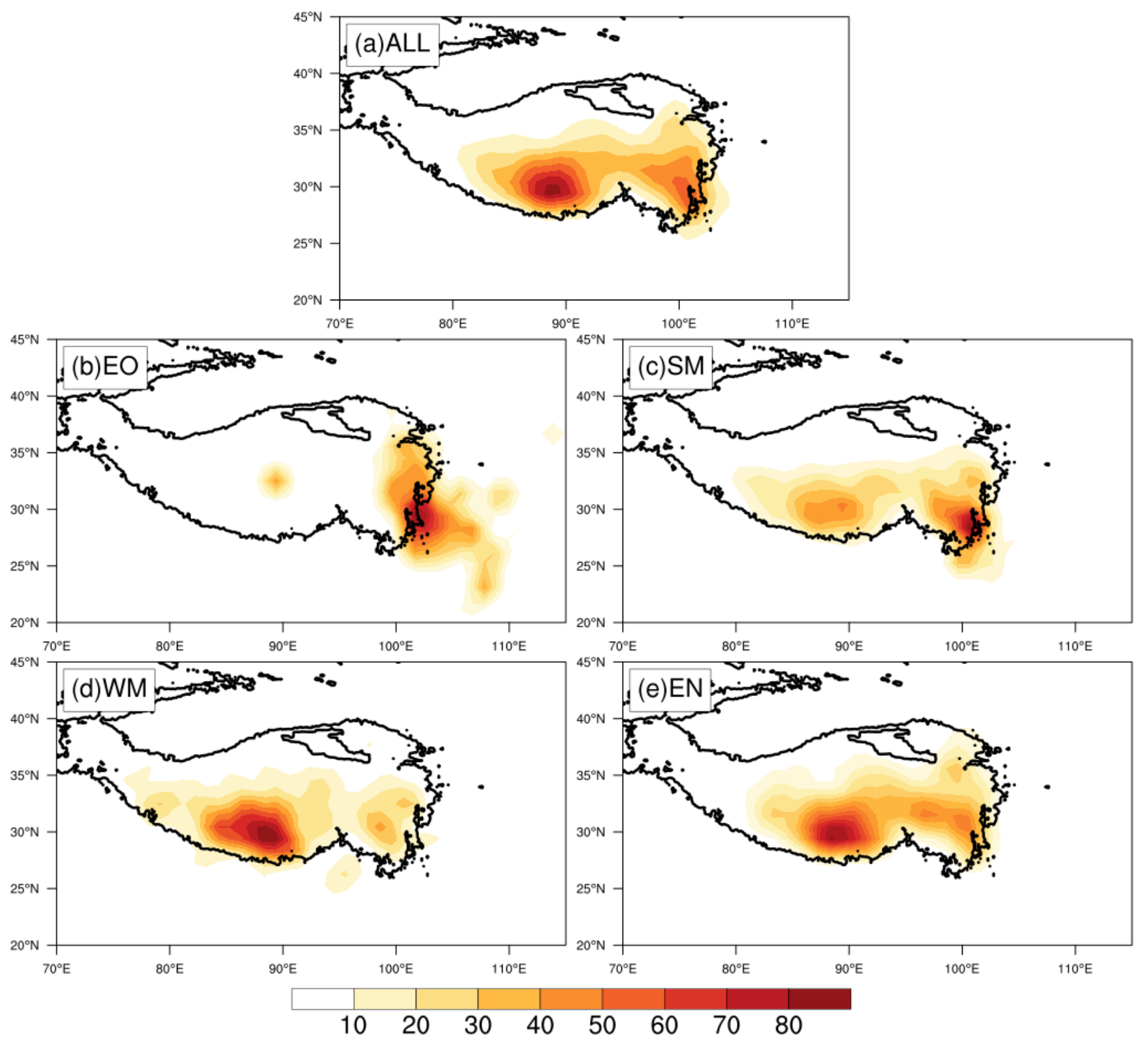

Figure 14. Spatial distribution of $\mathrm{P}_{\max }$ over the TP on $1^{\circ} \times 1^{\circ}$ grids. (a) All MCSs; (b) EOs; (c) SMs; (d) WMs; (e) ENs.

The differences in occurrence time $(\Delta t)$ between $\mathrm{BT}_{\min }$ and $\mathrm{P}_{\max }$ are shown in Figure 15. SMs, WMs and ENs showed similar features in each month. Among most events, the $\Delta t$ values ranged between -12 and $6 \mathrm{~h}$, and $\mathrm{BT}_{\min }$ occurred earlier than $\mathrm{P}_{\max }$ for more than $80 \%$ of MCSs. A $\Delta t$ of between -6 and $3 \mathrm{~h}$ was observed for $90 \%$ of non-EOs but only $80 \%$ of EOs. The proportion of EOs with positive $\Delta t$ is obviously larger than that of non-EOs. Results indicate that the peak in precipitation was usually followed by a minimum in brightness temperature over the TP. The occurrence of $\mathrm{BT}_{\min }$ ahead of $\mathrm{P}_{\max }$ is in agreement with what was obtained from a single cell [49], which can be explained by intense precipitation usually resulting from a rapid vertical updraft. The remaining MCSs for which $\mathrm{BT}_{\min }$ was followed by $\mathrm{P}_{\max }$ may be multi-cell convective systems. When some MCSs merge together, the updraft of the whole system may continue to grow after the precipitation reaches its maximum [44]. This may be a possible explanation for longlasting EOs. 

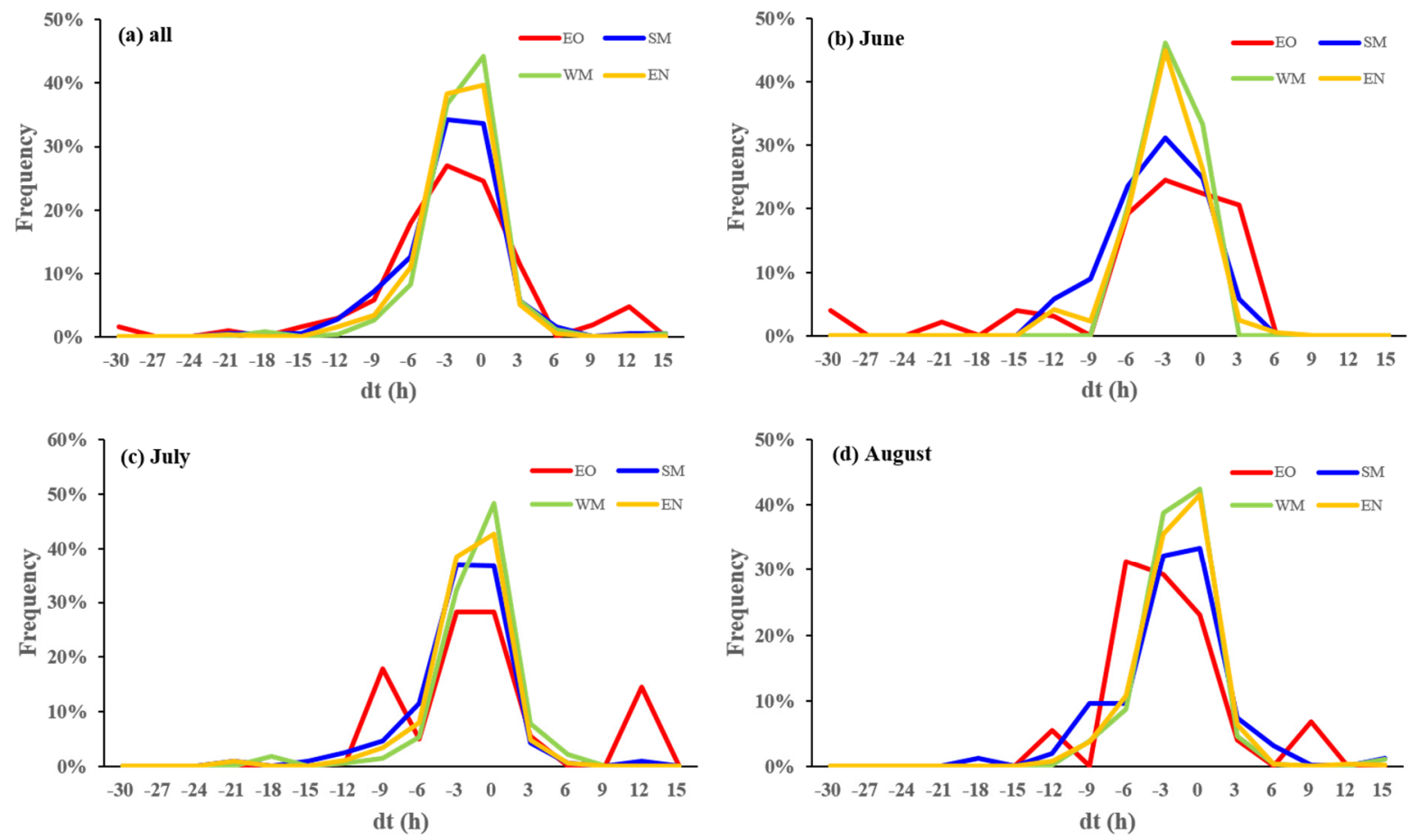

Figure 15. Difference in occurrence time ( $\Delta \mathrm{t}$ ) between $\mathrm{BT}_{\min }$ and $\mathrm{P}_{\max }$ for EOs (red), SMs (blue), WMs (green) and ENs (yellow). Negative $\Delta$ t means $\mathrm{BT}_{\min }$ occurs earlier than $\mathrm{P}_{\max }$. (a) Whole summer; (b) June; (c) July; (d) August.

\section{Discussions}

In this study, we found that no more than $15 \%$ of MCSs moved out of the TP, and EOs accounted for $9.3 \%$, which is similar to the $6.6 \%$ reported previously [35]. These results are much less than the value of $47 \%$ found in [36] and the value of $49 \%$ found in [26]. The mean life duration in this study was $12 \mathrm{~h}$, which is much shorter than the $36 \mathrm{~h}$ found in [36] but a few hours longer than that found in [26]. EOs in this study mainly influenced the regions east of $90^{\circ} \mathrm{E}$, whereas $\mathrm{Hu}$ et al. [26] indicated that some EOs may propagate to the east of Japan. These differences may be a result of the use of hourly satellite data and the precipitation criteria in the definition of MCSs in this study rather than the three-hourly data used elsewhere. The usage of coarse-resolution data may misclassify two independent MCSs into one and thus "prolong" the life duration and tracks. Moreover, as the zenith angle of the Fengyun satellite is less than that of other satellites, the hourly data used in this study should be more reliable for studying MCSs over the TP.

We used a strict definition of MCSs in this study based on both the rain intensity and the requirement of meeting four criteria in three successive hours. More physical parameters than in previous studies [35] were introduced to investigate the detailed statistical features of different types of MCSs. As there are fewer automatic weather stations over the western TP, the CMPA is mainly composed of the CMORPH precipitation product, and it may be inaccurate to some extent.

When EOs move out of the TP, they may induce a southwest vortex around the Sichuan Basin and further intensify rainfall downstream. In most cases, with the eastward movement, the southwest vortex impacts not only its genesis area but also the middle and lower reaches of the Yangtze River. The contributions of the dynamic and thermal processes to the formation of a southwest vortex may be complicated and vary in different cases. The relationship and interaction between EOs and southwest vortex will be investigated in future research. 


\section{Conclusions}

Based on the hourly Fengyun satellite infrared brightness temperature data and CMPA precipitation data, MCSs initiated over the TP in summer from 2013 to 2019 were examined statistically in this study. By investigating the occurrence frequency, life duration, temporal and spatial distribution, physical parameters and circulation and environmental features, some new findings were obtained.

During the seven summers, 8820 MCSs formed over the TP. Based on the direction of movement and tracks, MCSs were classified as EOs, SMs, WMs and ENs. The SMs, WMs and ENs showed similar features. Of all the MCSs, EOs, SMs, WMs and ENs accounted for $9.3 \%, 19.7 \%, 18.6 \%$ and $52.4 \%$, respectively, and the mean life duration of EOs was about $22 \mathrm{~h}$, nearly twice that of the non-EOs (SMs, WMs, ENs; about $12 \mathrm{~h}$ ). The number of MCSs initiated over the TP varied annually, with the maximum number of 1984 in 2016 and the minimum number of 670 in 2019, while the corresponding years for EOs were 2015 (maximum) and 2013 (minimum). Most MCSs occurred in July and August except for EOs (June), and the maximum frequency for EOs occurred at around 15:00 LST, which is an hour earlier than non-EOs.

There was much more MCS activity over the southern TP than the northern TP, with two maximum frequency centers along $30^{\circ} \mathrm{N}$ over the southwestern and southeastern TP. MCSs that formed west of $95^{\circ} \mathrm{E}$ could rarely move eastward out of the TP. EOs and SMs were mainly initiated over the southeastern center, whereas WMs and ENs mainly took place over the western one. EOs mainly influenced the regions east of $90^{\circ} \mathrm{E}$, and most of them affected southwestern China after vacating the TP. Moreover, SMs and WMs were also able to move out of the TP. Almost 15\% of all MCSs were able to leave this region.

Based on the lifetime physical parameters, some key features of different types of MCSs can be illustrated. EOs usually have a lower cloud-top temperature, greater rainfall intensity, longer life duration, more rapid development, larger areas of rainfall and convective clouds, longer tracks and wider influence range, indicating that EOs are more vigorous. The $\mathrm{BT}_{\min }$ and $\mathrm{P}_{\max }$ maximum centers of each type of MCS were located slightly downstream of the moving direction to the initiation area, and the maximum rain intensity of EOs was located east of the eastern boundary of the TP. The environmental circulations associated with different types of MCSs differ remarkably from each other. The movement of MCSs is mainly due to the mid- to high-level dynamic conditions, and moisture is an essential factor in the development and maintenance of MCSs.

Supplementary Materials: The following are available online at https:/ /www.mdpi.com/article/10 $.3390 / \mathrm{rs} 13091652$ /s1, Figure S1: Spatial distribution of MCSs initiation over the TP on $1^{\circ} \times 1^{\circ}$ grids in June. (a) All MCSs; (b) EOs; (c) SMs; (d) WMs; (e) ENs. Figure S2: Spatial distribution of MCSs initiation over the TP on $1^{\circ} \times 1^{\circ}$ grids in June. (a) All MCSs; (b) EOs; (c) SMs; (d) WMs; (e) ENs. Figure S3: Spatial distribution of MCSs initiation over the TP on $1^{\circ} \times 1^{\circ}$ grids in August. (a) All MCSs; (b) EOs; (c) SMs; (d) WMs; (e) ENs.

Author Contributions: Conceptualization, X.Z. (Xiaoyong Zhuge), S.Y. and Y.C.; methodology, X.Z. (Xidi Zhang) and W.S.; software, X.Z. (Xidi Zhang) and W.S.; validation, X.Z. (Xiaoyong Zhuge), Y.C., T.C. and S.Z.; formal analysis, X.Z. (Xidi Zhang) and X.Z. (Xiaoyong Zhuge); investigation, X.Z. (Xidi Zhang), S.Y. and Y.C.; resources, X.Z. (Xidi Zhang); data curation, X.Z. (Xidi Zhang); writing-original draft preparation, X.Z. (Xidi Zhang); writing-review and editing, X.Z. (Xidi Zhang), X.Z. (Xiaoyong Zhuge) and Y.C.; visualization, X.Z. (Xidi Zhang) and W.S.; supervision, X.Z. (Xiaoyong Zhuge), Y.C. and Y.W.; project administration, X.Z. (Xiaoyong Zhuge), S.Y., Y.C. and Y.W.; funding acquisition, X.Z. (Xiaoyong Zhuge), S.Y., Y.C. and T.C. All authors have read and agreed to the published version of the manuscript.

Funding: This research was funded by the National Key Research and Development Program of China (2018YFC1505704 and 2018YFC1505705), the National Natural Science Foundation of China (91837207, 91937301, 41930972), the Innovative Development Special Project of China Meteorological Administration (CXFZ2021Z033) and the Special Project of heavy rain forecasting expert innovation team of China Meteorological Administration (CMACXTD002-3). 
Institutional Review Board Statement: Not applicable.

Informed Consent Statement: Not applicable.

Data Availability Statement: Not applicable.

Acknowledgments: We appreciate the Fengyun satellite data provided by the National Satellite Meteorological Center of China Meteorological Administration (http:/ / satellite.nsmc.org.cn/PortalSite/ Data/Satellite.aspx, accessed on 13 July 2019). We also would like to thank the National Meteorological Information Center of China Meteorological Administration for the CMPA precipitation products (http:/ / data.cma.cn/data/cdcdetail/dataCode/SEVP_CLI_CHN_MERGE_CMP_PRE_ HOUR_GRID_0.10.html, accessed on 13 July 2019) and the European Center for Medium-Range Weather Forecasts for the ERA-5 reanalysis data (https:/ / cds.climate.copernicus.eu/cdsapp\#!/home, accessed on 13 July 2019). Last but not least, we thank the invaluable comments and suggestions by the anonymous reviewers that helped to greatly improve the quality of our manuscript.

Conflicts of Interest: The authors declare no conflict of interest.

\section{References}

1. Nesbitt, S.W.; Cifelli, R.; Rutledge, S.A. Storm Morphology and Rainfall Characteristics of TRMM Precipitation Features. Mon. Wea. Rev. 2006, 134, 2702-2721. [CrossRef]

2. Rasmussen, K.L.; Chaplin, M.M.; Zuluaga, M.D.; Houze, R.A., Jr. Contribution of Extreme Convective Storms to Rainfall in South America. J. Hydrometeorol. 2016, 17, 353-367. [CrossRef]

3. Carvalho, L.M.V.; Jones, C. A Satellite Method to Identify Structural Properties of Mesoscale Convective Systems Based on Maximum Spatial Correlation Tracking Technique (MASCOTTE). J. Appl. Meteorol. 2001, 40, 1683-1701. [CrossRef]

4. Vila, D.A.; Machado, L.A.T.; Laurent, H.; Velasco, I. Forecast and Tracking the Evolution of Cloud Clusters (ForTraCC) Using Satellite Infrared Imagery: Methodology and Validation. Wea. Forecast. 2008, 23, 233-245. [CrossRef]

5. Goyens, C.; Lauwaet, D.; Schröder, M.; Demuzere, M.; Van Lipzig, N.P.M. Tracking mesoscale convective systems in the Sahel: Relation between cloud parameters and precipitation. Int. J. Climatol. 2011, 32, 1921-1934. [CrossRef]

6. Aspliden, C.I.; Tourre, Y.; Sabine, J.B. Some Climatological Aspects of West African Disturbance Lines During GATE. Mon. Wea. Rev. 1976, 104, 1029-1035. [CrossRef]

7. Desbois, M.; Kayiranga, T.; Gnamien, B.; Guessous, S.; Picon, L. Characterization of Some Elements of the Sahelian Climate and Their Interannual Variations for July 1983, 1984 and 1985 from the Analysis of METEOSAT ISCCP data. J. Climate 1988, 1, 867-904. [CrossRef]

8. Payne, S.W.; McGarry, M.M. The Relationship of Satellite Inferred Convective Activity to Easterly Waves Over West Africa and the Adjacent Ocean During Phase III of GATE. Mon. Wea. Rev. 1977, 105, 413-420. [CrossRef]

9. Houze, R.A., Jr. Observed structure of mesoscale convective systems and implications for large scale heating. Quart. J. Roy. Meteorol. Soc. 1989, 115, 425-461. [CrossRef]

10. Mathon, V.; Laurent, H. Life cycle of Sahelian mesoscale convective cloud systems. Quart. J. Roy. Meteorol. Soc. 2001, 127, 377-406. [CrossRef]

11. Mathon, V.; Diedhiou, A.; Laurent, H. Relationship between easterly waves and mesoscale convective systems over the Sahel. Geophys. Res. Lett. 2002, 29, 1216. [CrossRef]

12. Mapes, B.E. Gregarious tropical convection. J. Atmos. Sci. 1993, 50, 2026-2037. [CrossRef]

13. Mapes, B.E.; Houze, R.A., Jr. Cloud clusters and superclusters over the oceanic warm pool. Mon. Wea. Rev. 1993, 121, 1398-1415. [CrossRef]

14. Chen, S.S.; Houze, R.A., Jr.; Mapes, B.E. Multiscale Variability of Deep Convection in Relation to Large-Scale Circulation in TOGA COARE. J. Atmos. Sci. 1996, 53, 1380-1409. [CrossRef]

15. Machado, L.A.T.; Rossow, W.B.; Guedes, R.L.; Walker, A.W. Life cycle variations of mesoscale convective systems over the Americas. Mon. Wea. Rev. 1998, 126, 1630-1654. [CrossRef]

16. Pope, M.; Jakob, C.; Reeder, M.J. Convective systems of the north Australian monsoon. J. Climate 2008, 21, 5091-5112. [CrossRef]

17. Zheng, Y.G.; Chen, J.; Zhu, P.J. Climatological distribution and diurnal variation of mesoscale convective systems over China and its vicinity during summer. Chin. Sci. Bull. 2008, 53, 1574-1586. [CrossRef]

18. Zheng, L.L.; Sun, J.H.; Zhang, X.L.; Liu, C.H. Organizational Modes of Mesoscale Convective Systems over Central East China. Wea. Forecast. 2013, 28, 1081-1098. [CrossRef]

19. Meng, Z.Y.; Yan, D.C.; Zhang, Y.J. General Features of Squall Lines in East China. Mon. Wea. Rev. 2013, 141, 1629-1647. [CrossRef]

20. Shen, R.; Reiter, E.R.; Bresch, J.F. Numerical Simulation of the Development of Vortices over the Qinghai-Xizang (Tibet) Plateau. Meteorol. Atmos. Phys. 1986, 35, 70-95. [CrossRef]

21. Wang, W.; Kuo, Y.H.; Warner, T.T. A Diabatically Driven Mesoscale Vortex in the Lee of the Tibetan Plateau. Mon. Wea. Rev. 1993, 121, 2542-2561. [CrossRef] 
22. Zhao, P.; Xu, X.D.; Chen, F.; Guo, X.L.; Zheng, X.D.; Liu, L.P.; Hong, Y.; Li, Y.Q.; La, Z.; Peng, H.; et al. The Third Atmospheric Scientific Experiment for Understanding the Earth-Atmosphere Coupled System over the Tibetan Plateau and Its Effects. Bull. Amer. Meteor. Soc. 2018, 99, 757-776. [CrossRef]

23. Tao, S.Y.; Ding, Y.H. Observational evidence of the influence of the Qinghai-Xizang (Tibet) Plateau on the occurrence of heavy rain and severe convective storms in China. Bull. Amer. Meteor. Soc. 1981, 62, 23-30. [CrossRef]

24. Hu, L.; Li, Y.D.; Fu, R.; He, J.H. The relationship between mobile mesoscale convective systems over Tibetan Plateau and the rainfall over eastern China in summer. Plateau Meteor. 2008, 27, 301-309. (In Chinese)

25. Fu, S.M.; Sun, J.H.; Zhao, S.X.; Li, W.L. The impact of eastward propagation of convective systems over the Tibetan Plateau on southwest vortex formation in summer. Atmos. Oceanic Sci. Lett. 2010, 3, 51-57.

26. Hu, L.; Deng, D.F.; Gao, S.T.; Xu, X.D. The seasonal variation of Tibetan convective systems: Satellite observation. J. Geophys. Res. Atmos. 2016, 121, 5512-5525. [CrossRef]

27. Wang, J.Y.; Wang, X.F.; Wang, X.K.; Cui, C.G. Statistical characteristics of eastward propagation of cloud clusters from the Tibetan Plateau and mesoscale convective systems embedded in these cloud clusters. Chin. J. Atmos. Sci. 2019, 43, 1019-1040. (In Chinese)

28. Zhang, S.L.; Tao, S.Y.; Zhang, Q.Y.; Zhang, X.L. Meteorological and hydrological characteristics of severe flooding in China during the summer of 1998. J. Appl. Meteor. Sci. 2001, 12, 442-457. (In Chinese)

29. Zhuo, G.; Xu, X.D.; Chen, L.S. Instability of eastward movement and development of convective cloud clusters over Tibetan Plateau. J. Appl. Meteor. Sci. 2002, 13, 447-456. (In Chinese)

30. Jiang, J.X.; Fan, M.Z. Convective clouds and mesoscale convective systems over the Tibetan Plateau in summer. Chin. J. Atmos. Sci. 2002, 26, 263-270. (In Chinese)

31. Zhang, S.L.; Tao, S.Y. The influence of Tibetan Plateau on weather anomalies over Changjiang River in 1998. Acta. Meteorol. Sin. 2002, 60, 442-452. (In Chinese)

32. Xu, X.D.; Chen, L.S. Advances of the study on Tibetan Plateau experiment of atmospheric sciences. J. Appl. Meteor. Sci. 2006, 17, 756-772. (In Chinese)

33. Shan, Y.; Lin, H.; Fu, W.C.; Jiang, J.X.; Huang, Q. The features of MCS during its initiation over Tibetan Plateau in summer. J. Trop. Meteorol. 2003, 19, 61-66. (In Chinese)

34. Jiang, J.X.; Xiang, X.K.; Fan, M.Z. The spatial and temporal distributions of severe mesoscale convective systems over Tibetan Plateau in summer. J. Appl. Meteor. Sci. 1996, 7, 473-478. (In Chinese)

35. Mai, Z.; Fu, S.M.; Sun, J.H.; Hu, L.; Wang, X.M. Key statistical characteristics of the mesoscale convective systems generated over the Tibetan Plateau and their relationship to precipitation and southwest vortices. Int. J. Climatol. 2021, 41, E875-E896. [CrossRef]

36. Li, Y.D.; Wang, Y.; Song, Y.; Hu, L.; Gao, S.T.; Fu, R. Characteristics of summer convective systems initiated over the Tibetan Plateau. Part I: Origin, track, development, and precipitation. J. Appl. Meteorol. Climatol. 2008, 47, $2769-2965$.

37. Hu, L.; Deng, D.F.; Xu, X.D.; Zhao, P. The regional differences of Tibetan convective systems in boreal summer. J. Geophys. Res. Atmos. 2017, 122, 7289-7299. [CrossRef]

38. Liu, Y.; Yao, X.P.; Fei, J.F.; Yang, X.R.; Sun, J. Characteristics of mesoscale convective systems during the warm season over the Tibetan Plateau based on FY-2 satellite datasets. Int. J. Climatol. 2021, 41, 2301-2315. [CrossRef]

39. Xu, W.X.; Zipser, E.J. Diurnal variations of precipitation, deep convection, and lightning over and east of the Eastern Tibetan Plateau. J. Climate 2011, 24, 448-465. [CrossRef]

40. Feng, Z.; Dong, X.Q.; Xi, B.K.; McFarlane, S.A.; Kennedy, A.; Lin, B.; Minnis, P. Life cycle of midlatitude deep convective systems in a Lagrangian framework. J. Geophys. Res. Atmos. 2012, 117, D23201. [CrossRef]

41. Xu, W.X. Precipitation and convective characteristics of summer deep convection over East Asia observed by TRMM. Mon. Wea. Rev. 2013, 141, 1577-1592. [CrossRef]

42. Yuan, J.; Houze, R.A., Jr. Global variability of mesoscale convective system anvil structure from A-Train satellite data. J. Climate 2010, 23, 5864-5888. [CrossRef]

43. Shen, Y.; Zhao, P.; Pan, Y.; Yu, J.J. A high spatiotemporal gauge-satellite merged precipitation analysis over China. J. Geophys. Res. Atmos. 2014, 119, 3063-3075. [CrossRef]

44. Ai, Y.F.; Li, W.B.; Meng, Z.Y.; Li, J. Life Cycle Characteristics of MCSs in Middle East China Tracked by Geostationary Satellite and Precipitation Estimates. Mon. Weather Rev. 2016, 144, 2517-2530. [CrossRef]

45. Pan, X.; Fu, Y.F. Analysis on Climatological Characteristics of Deep and Shallow Precipitation Cloud in Summer over QinghaiXizang Plateau. Plateau Meteor. 2015, 34, 1191-1203. (In Chinese)

46. Yang, R.Y.; Zhang, Y.C.; Sun, J.H.; Fu, S.M.; Li, J. The characteristics and classification of eastward-propagating mesoscale convective systems generated over the second-step terrain in the Yangtze River Valley. Atmos. Sci. Lett. 2019, 20, e874. [CrossRef]

47. Schröder, M.; König, M.; Schmetz, J. Deep convection observed by the Spinning Enhanced Visible and Infrared Imager on board Meteosat 8: Spatial distribution and temporal evolution over Africa in summer and winter 2006. J. Geophys. Res. Atmos. 2009, 114, D05109. [CrossRef]

48. Li, C.Y.; Wang, Z.T.; Lin, S.Z.; Cho, H.R. The relationship between East Asia summer monsoon activity and northward jump of the upper westerly jet location. Chin. J. Atmos. Sci. 2004, 28, 641-658. (In Chinese)

49. Houze, R.A., Jr. Mesoscale convective systems. Rev. Geophys. 2004, 42, RG4003. [CrossRef] 